\title{
ANÁLISE ANTINOCICEPTIVA E ANTI-INFLAMATÓRIA DO EXTRATO AQUOSO DE PIMPINELLA ANISUM PROVENIENTE DO SERTÃO DA PARAIIBA
}

\author{
ANTI-INFLAMMATORY AND ANTINOCICEPTIVE ACTIVITY OF THE \\ WATERY EXTRACT OF PIMPINELLA ANISUM FROM THE SERTÃO \\ OF PARAÍBA
}

\author{
Otávio Soares Nascimento ${ }^{1}$ \\ Vanessa Erika Abrantes Coutinho ${ }^{2}$ \\ Fernando Magno Bitú Magalhães ${ }^{3}$ \\ Wigna Luana de Figueirêdo Pimenta ${ }^{4}$ \\ Anne Carolline da Silva Linhares ${ }^{5}$ \\ Mariana Gomes Pinto ${ }^{6}$
}

RESUMO: Objetivo: Avaliar a atividade antinociceptiva e anti-inflamatória da espécie Pimpinella anisum. Método: Para as análises biológicas, foi obtido o extrato aquoso utilizando as sementes compradas no comércio da cidade de Cajazeiras, Paraíba - Brasil. Para a realização da atividade antinociceptiva foi realizado os testes de edema de pata induzido por formalina e o método de contorções abdominais induzido por ácido acético, para o teste de atividade anti-inflamatória foi utilizado o método de peritonite induzido pela carragenina. Resultados e discussão: Os resultados obtidos mostraram que o extrato aquoso de Pimpinella anisum apresentou atividade anti-inflamatória e antinociceptiva na dosagem de $200 \mathrm{mg} / \mathrm{kg}$. O extrato aquoso reduziu as contorções abdominais $(200 \mathrm{mg} / \mathrm{kg}=71 \%)$. O teste de formalina, a ação inibidora da erva sobre a nocicepção foi na segunda fase: $1^{\text {a }}$ fase $(200 \mathrm{mg} / \mathrm{kg}=05 \%)$ e $2^{\mathrm{a}}$ fase $(200 \mathrm{mg} / \mathrm{kg}=69 \%)$. No teste de peritonite foi possível avaliar a migração leucocitária, então observou-se que o extrato de Pimpinella anisum teve uma diminuição significante do número de leucócitos migrantes para a área afetada $(200 \mathrm{mg} / \mathrm{kg}=60 \%$ de inibiçãoo do grupo controle teste comparado ao

\footnotetext{
1 Biomédico. Graduado pela Faculdade Santa Maria.

2 Bacharela e Licenciada em Ciências Biológicas. Mestre em Biologia Celular e Molecular pela UFPB. Docente da Faculdade Santa Maria - FSM.

3 Farmacêutico. Mestre em Sistemas Agroindustriais pela UFCG.

4 Biomédica. Pós-Graduanda Especialização em Hematologia Clínica no Centro Universitário Leão Sampaio. Discente do Curso de Farmácia na Faculdade São Francisco da Paraíba.

5 Biomédica. Pós-Graduanda Especialização em Microbiologia Clínica na Faculdade Integrada de Patos.

${ }^{6}$ Acadêmica do curso de Fisioterapia da Faculdade Santa Mara - FSM.
} 
grupo controle negativo e $57 \%$ de inibição comparado ao grupo controle positivo). Com a obtenção desses dados é possível dizer que a Pimpinella anisum constitui princípios ativos capazes de inibir a dor e a inflamação.

Palavras chave: Pimpinella, Nociceptividade, Anti-inflamatório, Leucocitose.

ABSTRACT: Objective: To evaluate the antinociceptive and anti-inflammatory activity of the species Pimpinella anisum. Method: For the biological analysis, the aqueous extract was obtained using the seeds purchased in the commercial city of Cajazeiras, Paraíba - Brazil. For antinociceptive activity, formalin-induced paw edema tests were performed and acetic acid-induced abdominal writhing method was used for carrageenan-induced peritonitis method for anti-inflammatory activity test. Results and discussion: The results showed that the aqueous extract of Pimpinella anisum showed anti-inflammatory and antinociceptive activity at $200 \mathrm{mg} /$ $\mathrm{kg}$. The aqueous extract reduced abdominal writhing $(200 \mathrm{mg} / \mathrm{kg}=71 \%)$. The formalin test, the herb's inhibitory action on nociception was in the second phase: 1st phase $(200 \mathrm{mg} / \mathrm{kg}=05 \%)$ and $2 \mathrm{nd}$ phase $(200 \mathrm{mg} / \mathrm{kg}=69 \%)$. In the peritonitis test it was possible to evaluate leukocyte migration, so it was observed that Pimpinella anisum extract had a significant decrease in the number of migrating leukocytes to the affected area $(200 \mathrm{mg} / \mathrm{kg}=60 \%$ inhibition of the test group compared to the control group). negative control and $57 \%$ inhibition compared to the positive control group). By obtaining these data it can be said that Pimpinella anisum is an active ingredient capable of inhibiting pain and inflammation.

Keywords: Pimpinella, Nociception, Anti-inflammatory Agents, Leukocytosis. 


\section{INTRODUÇÃO}

As plantas medicinais vêm trazendo grandes inovações farmacológicas, abrangendo um amplo estudo sobre suas propriedades químicas (PEREIRA, 2013). A OMS descreve que a maioria da população tem a prática de utilização de chás, óleos, insumos, lambedores ou garrafadas, entre outros. Suas utilizações chegam a $80 \%$ da população mundial, proporcionando a descoberta de novos princípios ativos, trazendo um vasto benefício para medicina convencional (ANDRADE, 2016).

Durante muitos anos as pessoas manipulavam a natureza no intuito de realizar o tratamento de muitas doenças, aplicando produtos naturais para a urgência primária. O Sistema Único de Saúde (SUS) elaborou uma Relação de Plantas Medicinais de Interesse do SUS (RENISUS) em fevereiro de 2009, que foi implantada pelo Ministério da Saúde, priorizando plantas do conhecimento popular e de uso científico comprovado e que possibilitam o tratamento de doenças de nível comum (MARMIT et al., 2016).

Entre os países de maior variedade de espécies de plantas, encontra-se o Brasil, onde existe uma enorme biodiversidade, trazendo uma vasta área de pesquisas sobre o poder de princípios ativos farmacológicos extraídos de vegetais, que podem ser encontradas em seus extratos e oriundas de uma complexidade de moléculas ou substâncias, que alcançam o poder terapêutico em muitas doenças humanas. (BATISTA et al., 2016).

Dentre as plantas utilizadas popularmente encontra-se a espécie Pimpinella anisum, da família Umbelliferae, popularmente conhecida como anis ou erva doce, apresentando ação parasitária, antiemética, antibacteriana e antifúngica (BARAKAT et al., 2016). As folhas e principalmente as sementes são utilizados geralmente na forma de infusão, na terapia popular para vários fins terapêuticos como combater a digestão, dores estomacais, limpeza de pele, ressecamento, calmante, cólicas intestinais, má digestão. (CAETANO, 2015). Estudos mostram também sua função sobre a angiogênese e o combate ao câncer gastrointestinal, como também seu 
efeito neuroprotetor, evitando convulsões e limitando convulsões crônicas. (BEKARA et al., 2016).

Neste contexto, este trabalho tem como objetivo de analisar a erva doce (Pimpinella anisum) em parâmetros experimentais de inflamação e nocicepção, em modelo animal.

\section{MATERIAIS E MÉTODOS}

\section{Material Botânico}

As sementes da espécie Pimpinella anisum foi adquirida a partir de uma loja de produtos naturais no mês de outubro, no município de Cajazeiras, Paraíba, Brasil. O material comprado foi transportado até o laboratório de pesquisas da Faculdade Santa Maria, em Cajazeiras - PB.

\section{Preparação do Extrato}

Pra a obtenção do extrato, foram utilizados $40 \mathrm{~g}$ do material triturado, onde foi fervido por cinco minutos em $200 \mathrm{~mL}$ água mineral. Após cinco minutos em repouso, o material foi filtrado com papel filtro rendendo aproximadamente $180 \mathrm{~mL}$ de extrato, obtendo-se a infusão. 


\section{Animais}

Para a realização dos testes, foram utilizados 54 camundongos, (Mus musculus), albinos, variedade Swiss, adultosjovens, machos, de peso entre 25-30g, provenientes do biotério da Faculdade Santa Maria, Cajazeiras-PB. Os animais foram mantidos em gaiolas de polietileno, sob condições monitoradas de temperatura $\left(20 \pm 3^{\circ} \mathrm{C}\right.$, ) ciclo claro/escuro de 12 horas, sendo a fase clara de 06 às 18 horas, recebendo ração padrão Nuvilabß e água ad libitum disponíveis em garrafas de polietileno com bicos de inox.

\section{Condições Experimentais}

Todos os procedimentos foram realizados no laboratório de farmacologia, química e análises clínicas da Faculdade Santa Maria - FSM, no período compreendido das 07:00 às 21:00 horas. Nas 24 horas antecedentes aos experimentos, os animais foram divididos em grupos, contendo 06 animais cada, e mantidos na sala onde foi desenvolvido o estudo, a fim de adaptá-los ao ambiente experimental. Antes de cada procedimento as bancadas e os aparelhos utilizados foram higienizados com álcool a $70 \%$. A pesquisa foi conduzida em obediência às normas e diretrizes bioéticas vigentes para ensaios envolvendo seres vivos: animais (Guide for the Care and Use of Laboratory Animals, do NIH - National Institute of Health-EUA, 1996; Lei Federal No 11.794/2008; Conselho Nacional de Controle de Experimentação CONCEA); e integridade da fauna e flora (Lei Federal № 9605/1998) (MACHADO et al., 2004). O projeto foi aprovado pelo Comitê de Ética em Pesquisa Animal da Faculdade Santa Maria - FSM, com o número 05/2017. 


\section{Testes de nocicepção induzida por formalina}

Para o teste de Nocicepção, formaram-se grupos compostos por 6 animais, que foram utilizados para determinar a ação da Pimpinella anisum no teste da formalina. Nos camundongos do grupo controle negativo foram aplicados injeção de $20 \mu \mathrm{l}$ de formalina a $2 \%$ na pata direita traseira. Para o grupo controle positivo, os camundongos foram tratados com $10 \mu \mathrm{l}$ de morfina, meia hora antes da aplicação da injeção de $20 \mu \mathrm{l}$ de formalina a $2 \%$ na pata esquerda traseira. Uma hora antes, os camundongos do grupo controle teste, foram tratados com extrato aquoso da Pimpinella anisum na dose de $200 \mathrm{mg} / \mathrm{kg}$, via oral, e aplicada a injeção de $20 \mu \mathrm{l}$ de formalina a $2 \%$ na pata esquerda traseira. Logo em seguida da aplicação, os animais foram colocados individualmente, sob béquer de vidro invertido para a observação, como mostra a figura 01 . O tempo marcado (em segundos) em que o animal lambeu ou mordeu a pata foi registrado em duas fases: inicial (0-5 min) e tardia (20-25 min), após a administração da formalina, seguindo a metodologia descrita por Aquino em 2016.

Figura 01: Teste de Formalina. (A) Aplicação da Pimpinella anisum; (B) Injeção de Formalina; (C) Reação do Animal.

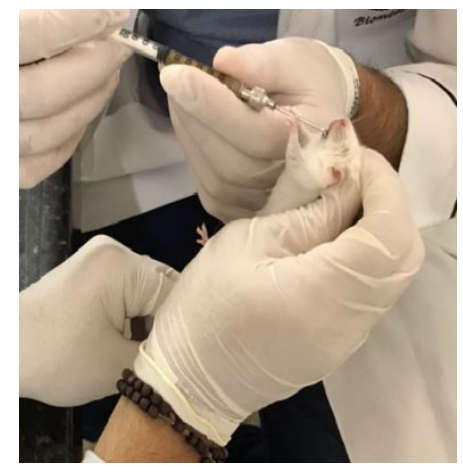

A

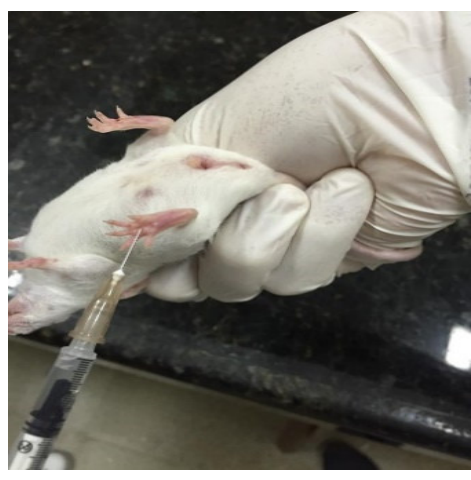

B

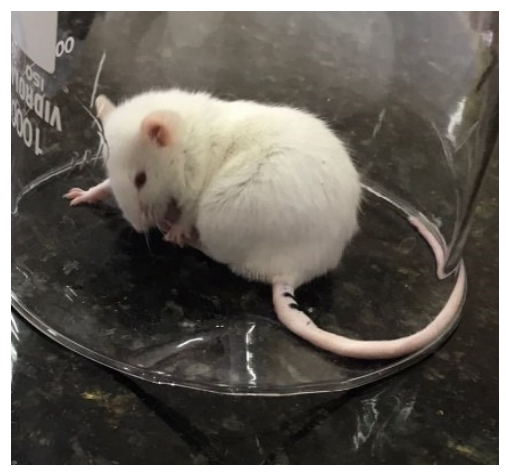

C

Fonte: Nascimento (2017). 


\section{Teste de contorções abdominais induzidas pelo ácido acético}

Para os testes de contorções abdominais induzidas pelo ácido acético, os camundongos foram divididos em 3 grupos, contendo 06 animais cada. No grupo controle negativo foi aplicado o ácido acético a 1\%, via intraperitoneal, e analisados durante 30 minutos, e contadas às contorções 10 minutos após a aplicação. No grupo controle positivo foram aplicados $10 \mu \mathrm{l}$ de morfina, e uma hora depois aplicado o ácido acético 1\%. Os animais foram observados por um tempo de 30 minutos, contando os números de contorções abdominais após 10 minutos a aplicação do ácido acético. O grupo controle teste, foi tratado com o extrato aquoso de Pimpinella anisum 200mg/kg uma hora antes, via oral, e após esse tempo foi aplicado o ácido acético $1 \%$, assim os camundongos foram analisados durante 30 minutos e iniciadas as contagens de contorções após 10 minutos a aplicação do ác. acético, como mostra a figura 02. As contorções abdominais foram analisadas e definidas como contorções de corpo inteiro pela extensão das patas traseiras (BATISTA et al., 2016).

\section{Peritonite induzida por carragenina}

No teste de ação anti-inflamatória, os camundongos foram divididos em 04 grupos contendo 06 animais cada. No grupo controle não foi utilizado nenhuma substância, apenas para a comparação de valores de referência de leucócitos. No controle negatio foi aplicada a carragenina a $1 \%$ via intraperitoneal. No controle positivo foram injetados a $10 \mu$ de morfina e após uma hora, aplicado a carragenina $1 \%$ via intraperitoneal. No grupo do teste os camundongos foram tratados com o extrato aquoso de Pimpinella anisum 200mg/kg, via oral. Esperou-se uma hora após a administração do extrato para a aplicação da carragenina $1 \%$ via intraperitoneal. Foram aguardados necessariamente 4 horas, para que ocorresse a migração de leucócitos para a região peritoneal. Para obtenção da amostra, aplicou-se $20 \mathrm{ml}$ de 
água destilada na cavidade peritoneal, posteriormente foi realizado uma leve massagem abdominal, como mostra a figura 02. Para as análises as amostras foram coletadas e depositadas em tubos contendo EDTA. Para a leitura do número total de leucócitos foi utilizado a Câmara de Neubauer e Líquido de Turk. Os camundongos foram eutanasiados por deslocamento cervical, seguindo protocolo de Do, Naturais; Silva (2016).

Figura 02: Teste de contorções abdominais induzidas pelo ácido acético. (A) Aplicação de Pimpinella anisum; (B) Injeção de ácido acético; (C) Reação do camundongo. llustração prática do teste de Peritonite induzida por Carragenina. D) Pimpinella anisum; E) Abertura/Peritônio; F) Coleta do liquido.

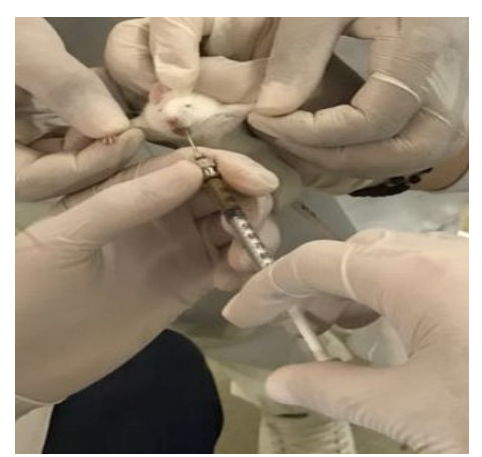

A

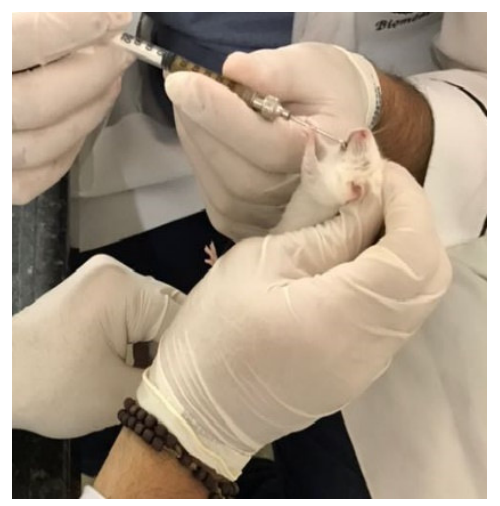

A

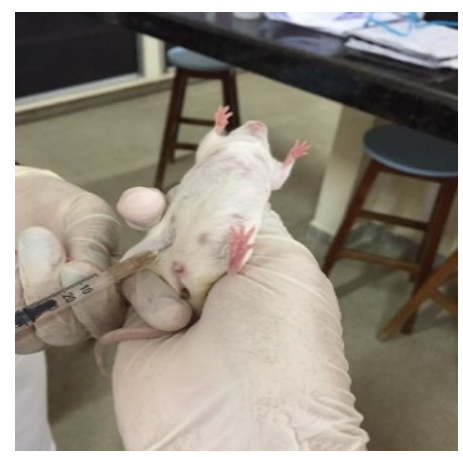

B

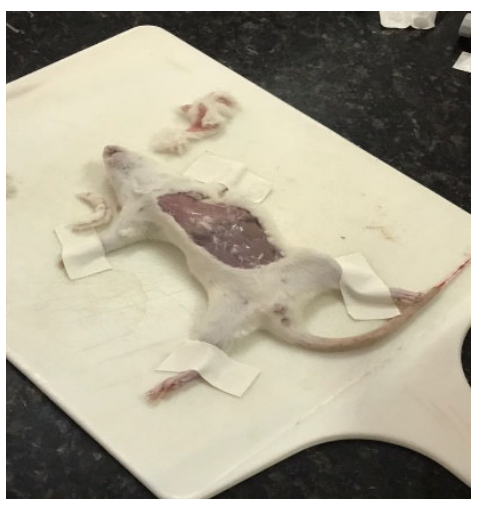

B

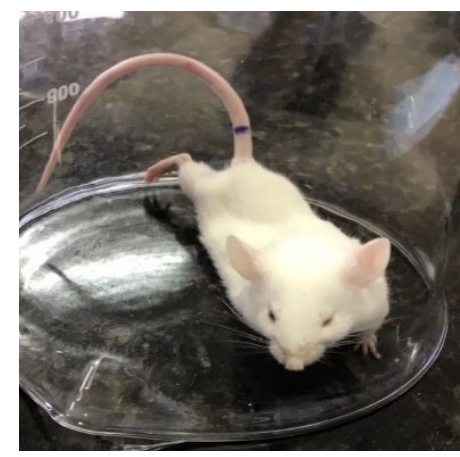

C

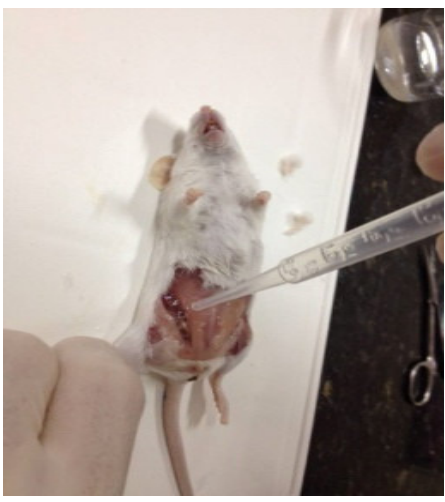

C

Fonte: Nascimento (2017). 


\section{Análise Estatística}

Os resultados das análises efetuadas foram analisados tomando como base a média e seu correspondente erro padrão.

\section{RESULTADOS E DISCUSSÕES}

Verificou-se que a aplicação do extrato aquoso de Pimpinella anisum como forma de pré-tratamento foi capaz de reduzir as contorções abdominais no parâmetro experimental no teste de ácido acético, reduzir significativamente o número de leucócitos migrantes para a região inflamatória no teste de peritonite e reduzir o tempo de lambedura no teste de formalina.

\section{Testes de formalina}

A aplicação do extrato de Pimpinella anisum em camundongos (figura 01) na dose de $200 \mathrm{mg} / \mathrm{kg}$ apresentou efeito de $7 \%$ sobre o tempo de lambedura da pata injetada com formalina no período da primeira fase do controle teste (0-5 minutos), comparado ao grupo controle negativo. Na segunda fase (20 - 25 minutos), reduziuse significativamente o tempo em $63 \%$ em que o animal permaneceu lambendo a pata em relação ao grupo controle negativo.

Aplicação do extrato de Pimpinella anisum, na dose de $200 \mathrm{mg} / \mathrm{kg}$ causou uma inibição de $69 \%$ na segunda fase de tratamento. A morfina $10 \mu / / k g . i . p$. foi utilizada como fármaco padrão, pois sendo ela um analgésico opióide, foi capaz de inibir em $63 \%$ na primeira fase o tempo de lambedura da pata e em $100 \%$ na segunda fase desse teste. 
Figura 03: Os valores em cada coluna representam a média e desvio padrão do tempo de lambedura do animal.

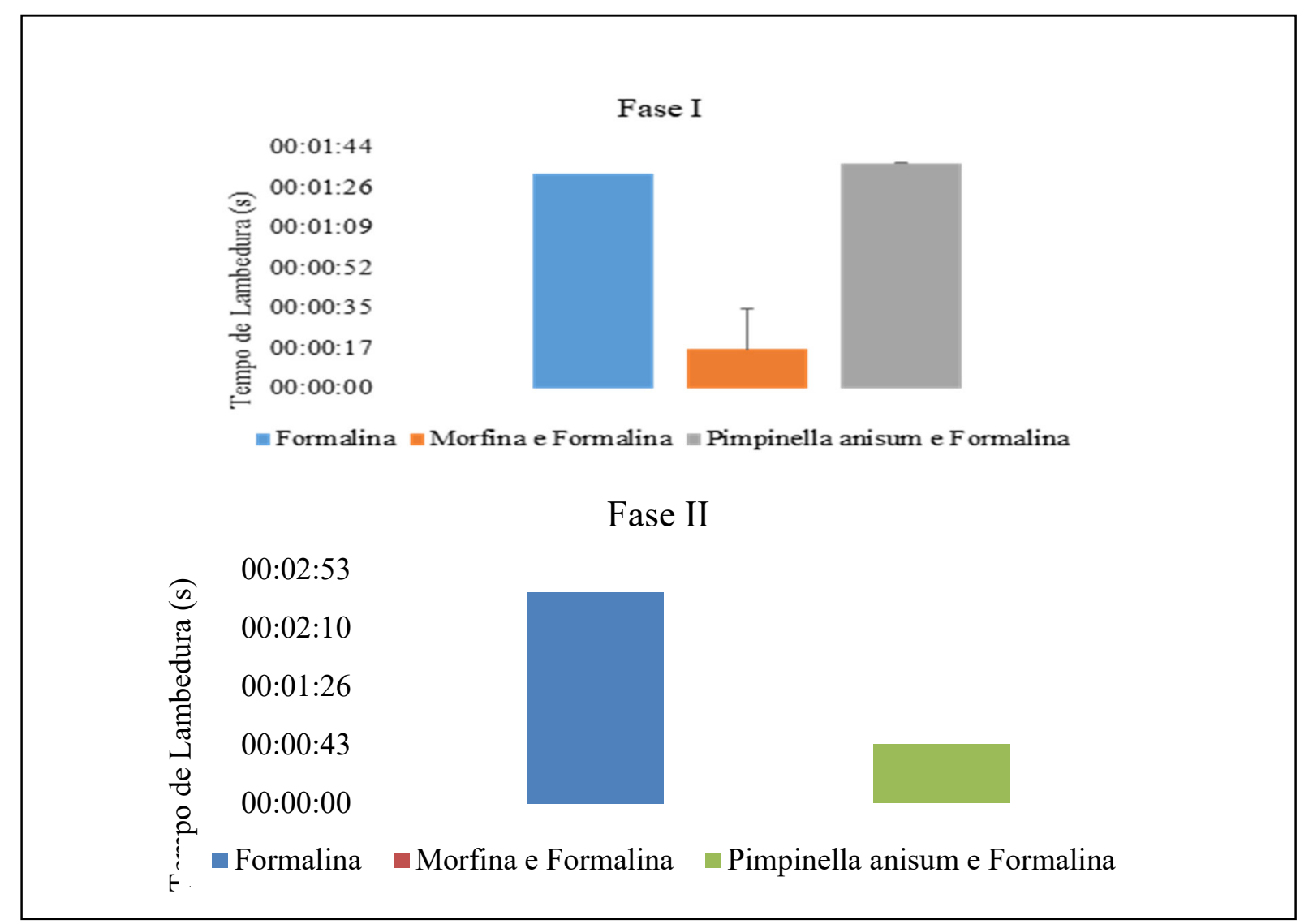

Fonte: Nascimento (2017).

Com aplicação da formalina na pata traseira de camundongos como é destacada na figura é possível analisar o comportamento do animal diante uma lesão tecidual ocasionado pela injeção subcutânea do formaldeído, onde o animal demonstra ações de maneira quantificada ao teste (SILVA et al., 2013). Com a introdução da formalina, é possível analisar duas fases: a aguda que se prolonga nos primeiros 5 minutos e a tardia ou inflamatória que se estende dos 15 minutos a 30 minutos. As duas fases caracterizam estágios diferenciais, tornando-se favorável para a avaliação de fármacos de ação central, como a morfina, e anti-inflamatórios não esteroidais (ASSIS, 2016).

Os fármacos que atuam no nível de sistema nervoso central como os opióides, podem suprimir as duas fases desse teste inibindo a ação nociceptiva 
acarretada pela formalina. Enquanto as drogas que atuam no nível de sistema nervoso periférico atuam suprimindo a segunda fase do teste. A tardia tem a participação de vários mediadores inflamatórios que atuam na dor inflamatória, esses são receptivos a fármacos de ação anti-inflamatória não esteroidal (SANTOS et al., 2015).

A inibição da segunda fase do teste de formalina, pela aplicação do extrato aquoso de Pimpinella anisum foi de $69 \%$, reduzindo significativamente o tempo de lambedura de pata do camundongo, como mostra na Figura 03. Proporcionando uma ação antinociceptiva, sugerindo uma diminuição dos mediadores da inflamação.

\section{Testes de contorções abdominais induzidas pelo ácido acético}

No teste de contorção abdominal induzida pelo ácido acético $1 \%$, a administração do extrato aquoso de Pimpinella anisum foi de $200 \mathrm{mg} / \mathrm{kg}$, essa aplicação foi capaz de reduzir a resposta à dor induzida pelo ácido acético em $71 \%$, comparado ao grupo controle negativo. O fármaco padrão utilizado no grupo teste positivo foi a morfina $10 \mu \mathrm{l} / \mathrm{kg}$, aplicado meia hora antes da aplicação do ácido acético $1 \%$ foi capaz de zerar o número de contorções, por isso não foi representada no gráfico.

Figura 04: Os valores em cada coluna representam à média e desvio padrão do número de contorções do animal.

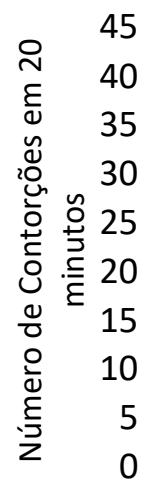

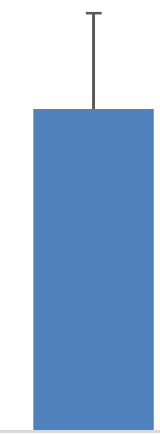

ÁC. ACÉTICO

Fonte: Nascimento (2017).

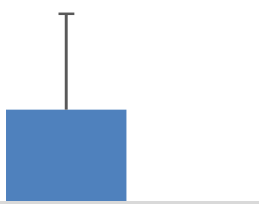

Pimpinella anisum 
$\mathrm{Na}$ atividade de contorções abdominais, induzido pelo ácido acético, como mostra a figura 02, é um teste realizado com uma alta sensibilidade para análises de fármacos antinociceptivos, a dor gerada nesse tipo de teste, provoca a liberação múltiplos mediadores como prostaglandinas, histaminas, bradicinina e serotonina, causando estímulos aos receptores sensoriais periféricos, os nociceptores, no que Ihes concernem sensibilidade aos AINES (anti-inflamatórias não-esteroidais) e narcóticos (BATISTA et al., 2016).

Comparando os dados apresentados nos testes de contorção abdominal do grupo controle negativo com o grupo controle positivo, observa-se a relevância da ação do extrato no controle teste, destacando a hipótese de que exista uma inibição dos mediadores da inflamação.

Assim, é possível destacar que o teste de contorções abdominais apresentouse relevante, comparando os demais grupos com o grupo controle negativo, como mostra a Figura 04, é justificável salientar a existência de vias de ações inflamatórias.

Araujo (2013) realizou testes de nocicepção com o extrato bruto etanólico de sementes de Pimpinella anisum, por meio do teste de contorções abdominais induzido pelo ácido acético, com dosagem de $298 \mathrm{mg} / \mathrm{kg}$, assim obtendo a diminuição do número de contorções, com isso os resultados tornaram-se satisfatórios.

De acordo com Souza (2013) o extrato etanólico de Foeniculum vulgare Mill, da família Umbelliferae/Apiaceae apresentou atividade antinociceptiva no teste de contorção abdominal induzido pelo ácido acético, como também as frutas da erva doce apresentaram e atividade anti-inflamatória, analgésica e antioxidante. Mostrando que a Pimpinella anisum pode agir inibindo a dor e apresentar ação bloqueadora das vias de inflamação. 


\section{Peritonite induzida por carragenina em camundongos}

No intuito de avaliar o efeito do extrato aquoso de Pimpinella anisum no sistema de defesa imunológico, o teste de peritonite induzida por carragenina em camundongos, causou uma acentuada migração leucocitária, respectivamente nos dois grupos: controle carragenina causou um aumento de 55\% e grupo controle morfina um aumento de $51 \%$, comparados ao grupo padrão.

O extrato aquoso de Pimpinella anisum 200mg/kg inibiu em $60 \%$ a migração leucocitária do grupo teste, comparado ao grupo controle negativo (carragenina) e em $57 \%$ de inibição comparado ao grupo controle positivo (morfina). Essas pesquisas constam uma inibição das células leucocitárias envolvidos no processo de inflamação desenvolvido pela carragenina.

Figura 05: Análise da ação do extrato aquoso de Pimpinella anisum sobre a peritonite induzida pela Carragenina. Os valores em cada coluna representam à média e desvio padrão do número de leucócitos.

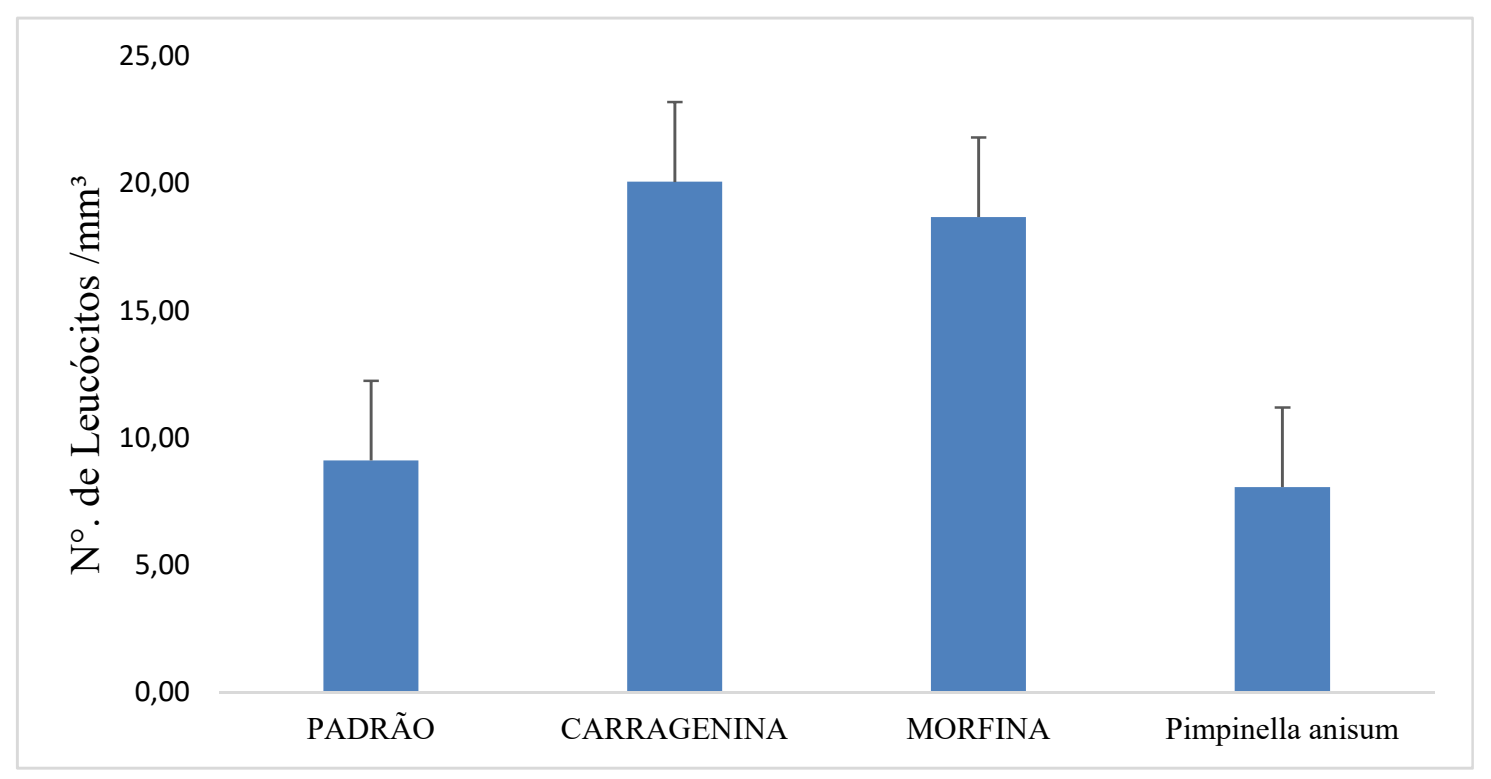

Fonte: Nascimento (2017). 
De acordo com MOTTA et al 2013, a inflamação é classificada em aguda ou crônica. A aguda inicia-se como processo inicial da lesão tecidual e celular, neste processo predomina-se a dilatação vascular e migração leucocitária. Assim, se os agentes causadores da inflamação não forem eliminados ocorrerá o estágio de cronicidade. Os estudos dos processos de inflamação agudo e crônico são importantes nos modelos animais, podendo assim nos testes quantificar os números de leucócitos que migraram para a área afetada, como os da cavidade peritoneal no teste de peritonite (PEREIRA, 2013).

Os carragenanos são agentes causadores de processos inflamatórios Batista (2016) a obtenção desse polissacarídeo é dada pela extração em algas. Os estudos sobre inflamação do peritônio em modelo animal é possível analisar as características e sinais acometidos no animal, esse processo é notado nas primeiras quatro horas após a aplicação da carragenina. Liberação da serotonina e histamina, como também uma concentração de permeabilidade celular é descrita na primeira hora após a aplicação. Na segunda hora, o aumento é proveniente das cininas, que são agentes vasoativas como bradicinina e devido às citocinas IFN- $\gamma, \mathrm{IL}-1 \beta$, IL-2 e TNF- $\alpha$. Assim, a terceira e quarta fase é considerada a mais intensa, pois ocorre liberação de óxido nítrico e prostaglandina (NETO, 2016).

O número de leucócitos que acabam migrando para o peritônio, são consequências da inflamação local, causando aumento do soluto entre as membranas porosas. Esse processo é causado pela vasodilatação capilar e maior abertura dos poros nos microvasos, promovido pelos mediadores inflamatórios, apresentando neutrófilos e prostaglandina.

Considerando esses estudos realizados, foi efetuado o teste de peritonite induzido por carragenina, no intuito de investigar ação do extrato aquoso de Pimpinella anisum na migração leucocitária. Com a aplicação da carragenina foi possível investigar um grande extravasamento plasmático com presença significante de leucócito na região peritoneal. Esse deslocamento celular pode ser acometido pelo bloqueio dos receptores de adesão molecular ou por quimiotaxia, permitindo a segregação de células inflamatórias no local afetado, portanto as células migratórias podem combater a lesão e agente agressor. O pré-tratamento com extrato de 
Pimpinella anisumreduziu de forma significativa o número de leucócitos migrantes no local inflamado do peritônio (Figura 05).

Paiva (2013) realizou estudos sobre o extrato etanoico de Pseudobombax marginatum, onde demonstrou ter efeito sobre ação de migração leucocitária de 48\% na dosagem do extrato de $200 \mathrm{mg} / \mathrm{Kg}$.

O teste realizado pôde demonstrar que o extrato aquoso de Pimpinella anisum, desenvolveu atividade de inibição no número de leucócitos, assim comparando o grupo controle positivo com o grupo teste e o estudo realizado por Paiva (2013) é possível ver a ação da taxa de diminuição do número de leucócitos. Comprovando sua ação no teste realizado.

\section{CONCLUSÃO}

A obtenção dos dados do presente trabalho mostrou que a Pimpinella anisum atuou de forma antinociceptiva inibindo os receptores de dor, mostrando de forma quantitativa e qualitativa esses dados, como também foi possível analisar a atividade anti-inflamatória inibindo a segregação leucocitária na região inflamada, comprovando sua ação nos testes.

Através dos testes realizados nessa pesquisa, não é possível saber de forma isolada o composto químico responsável pelos resultados obtidos. Em um extrato bruto, as substâncias presentes podem agir de diversas maneiras, assim os testes realizados foram fases iniciais para a proposição medicinal dessa planta como possibilidades de obter os metabólitos que possam ser utilizados pela indústria farmacêutica no combate de possíveis patologias.

Adquirir conhecimentos da Pimpinella anisum através de estudos e pesquisas é de grande importância para a utilização do seu potencial medicinal, servindo como interesse de uso farmacêutico, através de formulações medicamentosas eficazes e seguras, como para população que já faz uso dessa planta. 


\section{REFERÊNCIAS BIBLIOGRÁFICAS}

ANDRADE, Carolina Gonçalves. Analgesia e antissepssia do extrato de Acmella oleracea na pele: ensaio clínico aleatório. 2016. Tese de Mestrado.

AQUINO, Pedro Everson Alexandre de. Atividade anti-inflamatória e antinociceptiva da NMetil-Trans-4-Hidroxi-L-Prolina isolado das folhas de Sideroxylon obtusifolium. 2016. Tese de Doutorado.

ARAUJO, R,O et al. Avaliação biológica de Foeniculum vulgare (Mill.) (Umbelliferae/Apiaceae). Rev. Bras. PI. Med., Campinas, v.15, n.2, p.257-263, 2013.

ASSIS, Davidson Barbosa et al. Efeito antinociceptivo do fenilpropanóide 2-alilfenol. 2016. BARAKAT, D. et al. Anise (Pimpinella anisum) enhances the growth performance, immunity and antioxidant activities in broilers.International Journal of Pharmaceutical Sciences Review and Research, v. 37, n. 24, p. 134-140, 2016.

BATISTA, EKF et al. Atividades antinociceptiva e antiinflamatória do extrato etanólico de Luehea divaricata. Rev. bras. plantas med, v. 18, n. 2, p. 433-441, 2016.

BEKARA, A. et al. Effect os Pimppinella anisum L. on histological and biochemical damage in cerebrum and cerebelllum of Young rats intoicated by lead acetate. Group, v. 11, p. 12, 2016.

CAETANO, NLB et al. Plantas medicinais utilizadas pela população do município de Lagarto-SE, Brasil-ênfase em pacientes oncológicos. Rev. bras. plantas med, v. 17, n. 4, supl. 1, p. 748-756, 2015.

DO, NATURAIS; S. H. N. Avaliação do potencial antinociceptivo e anti-inflamatório do extrato etanólico bruto das folhas de atemoia (Annona cherimola Mill. x Annona squamosa L.) em roedores. 2016.

MARMITT, Diorge Jônatas et al. Análise da produção científica do Curcuma longa L.(açafrão) em três bases de dados após a criação da RENISUS. Revista Pan-Amazônica de Saúde, v. 7, n. 1, p. 71-77, 2016.

PAIVA, Dayane Carla Costa et al. Anti-inflammatory and antinociceptive effects of hydroalcoholic extract from Pseudobombax marginatum inner bark from caatinga potiguar.Journal of ethnopharmacology, v. 149, n. 2, p. 416-421, 2013.

PEREIRA, Charlane Kelly Souto et al. Atividade antinociceptiva e anti-inflamatória de Herissantia crispa (L.) Brizicky em camundongos. 2013.

SANTOS, R. K. L.; SÁ V. M. L.; FECHINE, I. M. Uso de analgésicos opioides e não opioides por pacientes idosos no controle da dor oncológica. 2015.

SILVA, Juliane Cabral et al. Modelos experimentais para avaliação da atividade antinociceptiva de produtos naturais: uma revisão. Brazilian Journal of Pharmacy, v. 94, p. 18-23, 2013.

SOUSA NETO, Benedito Pereira de. Atividade anti-inflamatória do derivado benzoiltriptaminico $n$-saliciloiltriptamina (NST) em modelos animais 2017.

SOUZA, I. A. et al. Avaliação biológica de Foeniculum vulgare (Mill.) (Umbelliferae/Apiaceae) Biological evaluation of Foeniculum vulgare (Mill.) (Umbelliferae/Apiaceae). Revista Brasileira de Plantas Medicinais, v. 15, n. 2, p. 257-263, 2013. 